
\title{
Reseserch Suare \\ Regenerative and anti-inflammatory effect of a novel bentonite complex on burn wounds
}

\author{
Ju Young Lee \\ Korea Institute of Toxicology \\ Han Na Suh \\ Korea institute of toxicology \\ Kwan Young Choi \\ C\&L Biotech Co. Ltd \\ Chang Woo Song \\ Korea institute of toxicology \\ Jeong Ho Hwang ( $\sim$ jeongho.hwang@kitox.re.kr) \\ Korea institute of toxicology https://orcid.org/0000-0001-9118-0905
}

\section{Research Article}

Keywords: anti-inflammation, bentonite, skin tissue regeneration, minipig burn wound model

Posted Date: November 5th, 2021

DOI: https://doi.org/10.21203/rs.3.rs-1033590/v1

License: (c) (1) This work is licensed under a Creative Commons Attribution 4.0 International License. Read Full License 


\section{Abstract \\ Background}

Bentonite, a montmorillonite clay, has been used as a classical remedy strategy for a long time. Recently, bentonite has been used as a raw material in cosmetic products because of its antibacterial and antioxidant properties. However, the therapeutic effect of bentonite on burn injuries has not yet been identified. Here, we explored the therapeutic effect of a novel bentonite complex, which was developed for medical use, on burn wounds and the anti-inflammatory function of bentonite clay in the complex in vitro.

\section{Methods}

A novel bentonite complex and bentonite clay were provided by C\&L Biotech Co., Ltd. (Seoul, Korea). The elements of bentonite clay were analysed using inductively coupled plasma optical emission spectroscopy. Burn wounds were induced on the dorsal skin of two Yucatan minipigs, and tissue regeneration was determined by cell proliferation, angiogenesis, and collagen deposition using immunohistochemistry and Masson's trichrome staining. Anti-inflammatory function was determined using quantitative real-time PCR and enzyme-linked immunosorbent assays.

\section{Results}

We found that by inducing collagen synthesis, cell proliferation, and angiogenesis, the bentonite complex improved skin regeneration in burn wounds. It was also identified that the expression of inflammatory cytokines associated with cyclooxygenase 2 (COX-2) signalling was significantly inhibited by treatment of the burn wounds with the bentonite complex. An in vitro study to identify the anti-inflammatory effect of bentonite clay, a major component of the bentonite complex, showed that COX-2 signalling was significantly regulated in both HacaT keratinocytes and 3D4/2 macrophage cell lines in vitro.

\section{Conclusions}

This study identified the therapeutic effect of a novel bentonite complex in burn wounds by inducing skin regeneration and bentonite-mediated anti-inflammatory responses with bentonite complex treatment.

\section{Background}

A burn is one of the most severe injuries caused by contact with a hot object, fire, and even chemical agents $[1,2]$. Burn wounds are classified into three degrees based on wound depth and total body surface area (TBSA) [3]. Patients with high degree burns ( $>40 \%$ of TBSA) are vulnerable to pathogenic infection through a broken epidermal layer [4]. Burn wounds recover through a complex process, which is classified into four phases in the order of cutaneous hemostasis, regulation of inflammation, cell proliferation, and 
tissue remodelling [5-7]. The management and treatment of burn wounds has been accomplished by facilitating the progression of the recovery phases. Thus, researchers and medical companies are struggling to find novel materials that promote regeneration and anti-inflammation [8,9].

Bentonites, which originate from altered volcanic ash, have been used as major components in cosmetic and medical products [10-13]. Formerly, bentonite has been considered a therapeutic material and even applied to wounds in cases of emergencies [14]. Recently, the biological functions of bentonites have been reported in various studies. Due to their physical characteristics, bentonites effectively remove toxins and protect against pathogenic infections caused by skin injury [15]. In addition, some studies have reported that bentonites improve cell migration, expansion, spreading, and differentiation. [16]. Nevertheless, the therapeutic effects of bentonite on burn wounds have not yet been identified.

Using a minipig burn wound model, we explored the therapeutic effects of a novel bentonite complex developed for medical use (C\&L Biotech, Seoul, Korea). Minipigs were chosen because their skin is similar to those of humans in terms of tissue structure and physiological and immunological contents [17-19]. Burn inducement and post-management were performed in the same manner as previous studies [20,21]. Skin regeneration was evaluated using macroscopic and microscopic investigations. Contraction of the wound area, scab formation, and inflammatory phenotypes were examined by macroscopic observation [22]. To analyse microscopic phenotypes of wound healing, the expressions of Ki67, VEGF, and collagen deposition were measured by immunohistochemistry $(\mathrm{IHC})$ and Masson's trichrome staining methods [2326]. The anti-inflammatory effect of the bentonite complex was determined by analysing the inhibition of cyclooxygenase 2 (COX-2) / prostaglandin E2 (PGE2) signalling using quantitative real-time PCR (qRTPCR) and enzyme-linked immunosorbent assay (ELISA) methods. [27,28]. Furthermore, to identify the anti-inflammatory function of bentonite clay, a major component of the bentonite complex, the expressions of COX-2-associated cytokines were analysed in keratinocyte and macrophage cell lines, which constitute the dermal immune system $[29,30]$.

\section{Materials And Methods}

\section{Materials}

The bentonite complex was provided by C\&L Biotech Co. Ltd.. The ingredients of the bentonite complex are listed in Table 1. The bentonite complex for the in vivo assay was prepared at two concentrations (T1, $1 \mathrm{mg} / \mathrm{mL} ; \mathrm{T} 2,6 \mathrm{mg} / \mathrm{mL}$ ) to evaluate dose dependency. Silver sulfadiazine $1 \%$ cream (Dongwha Pharm Co. Ltd, Seoul, South Korea) and saline solution were used for each positive control (PC) and negative control (NC). 
Table 1

Components of bentonite complex

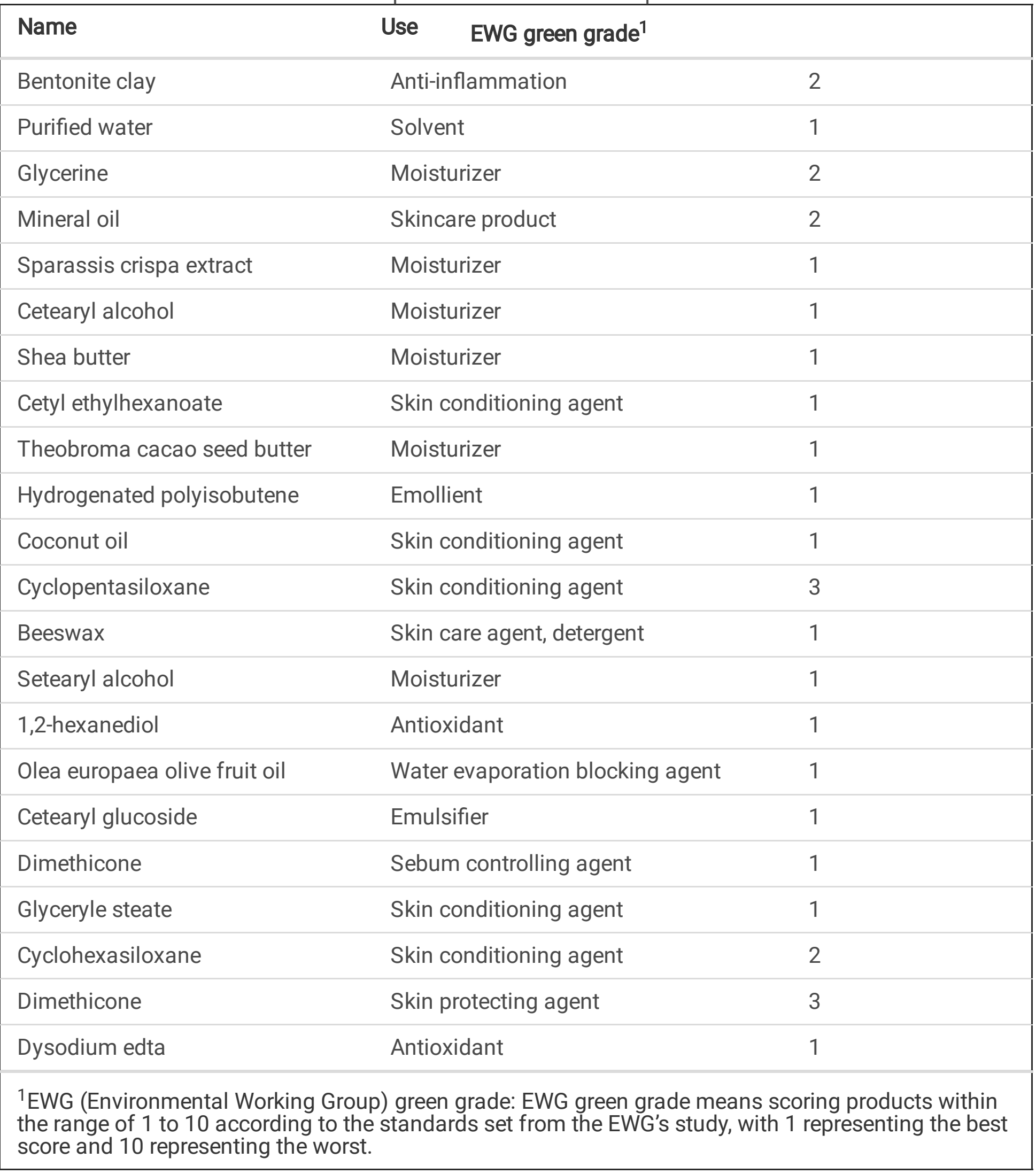

For the in vitro assay, bentonite clay (C\&L Biotech Co. Ltd) was autoclaved at $121^{\circ} \mathrm{C}$ for $1 \mathrm{~h}$. The specific elements of the bentonite clay in the mixture were precisely measured using inductively coupled plasma optical emission spectroscopy (ICP-OES, Agilent ICP-MS 7700S, Table 2). Sterilised bentonite clay was 
suspended in $1 \mathrm{~mL}$ of UV-irradiated phosphate buffered saline, diluted 10 -fold $(100,10$, and $1 \mu \mathrm{g} / \mathrm{mL})$, and incubated for $1 \mathrm{~h}$ at room temperature. The solution was centrifuged at $13,000 \times \mathrm{g}$ for $2 \mathrm{~h}$ to elute the soluble fraction to avoid physical damage to the cell lines. The supernatant was carefully collected and passed through a $0.22 \mu \mathrm{m}$ micropore filter to remove any insoluble debris.

Table 2

The elements of bentonite clay

\begin{tabular}{ll}
\hline Elements & Detection limit (m \\
\hline $\mathrm{Li}$ & $44.6 \pm 8.7$ \\
$\mathrm{~B}$ & $5661.5 \pm 483.5$ \\
$\mathrm{Na}$ & $32950 \pm 10855$ \\
$\mathrm{Mg}$ & $8455 \pm 105$ \\
\hline $\mathrm{Al}$ & $50400 \pm 3200$ \\
\hline $\mathrm{Si}$ & $209500 \pm 19500$ \\
\hline $\mathrm{K}$ & $19400 \pm 400$ \\
\hline $\mathrm{Ca}$ & $14450 \pm 250$ \\
\hline $\mathrm{Ti}$ & $2070 \pm 30$ \\
\hline $\mathrm{V}$ & $27.95 \pm 0.45$ \\
\hline $\mathrm{Cr}$ & $44.65 \pm 1.55$ \\
\hline $\mathrm{Mn}$ & $289 \pm 5$ \\
\hline $\mathrm{Ni}$ & $79.4 \pm 11.2$ \\
\hline $\mathrm{Cu}$ & $8.03 \pm 0.85$ \\
\hline $\mathrm{Zn}$ & $65.4 \pm 9.2$ \\
\hline $\mathrm{Sr}$ & $370.5 \pm 15.5$ \\
\hline $\mathrm{Ba}$ & $694 \pm 26$ \\
\hline $\mathrm{Pb}$ & $121 \pm 16$ \\
\hline & \\
\hline
\end{tabular}

The elements of the bentonite clay were measured by ICP-OES. Detection limit is represented as mean \pm standard deviation $(n=2)$.

\section{Animals}

Male and female Yucatan minipigs (Sus scrofa domesticus; Optipharm, Cheongju Korea), aged 7-8 months old and weighing 9.5-12.5 kg, were subjected to surgery to create burn wounds. They were bred in individual cages under specific pathogen-free (SPF) and controlled conditions (40-60\% humidity; $12 \mathrm{~h} / 12$ 
h light/dark cycle). Water was provided ad libitum, and food (Purina, St. Louis, USA) was provided daily at $2 \%$ of the body weight. Clinical status was monitored every morning, and checkpoints were increased to twice a day after surgery. A designated photographer recorded macroscopic observations by taking pictures of each woundon days 2,10 , and 21 (necropsy).

For burn induction, the minipigs were anaesthetized by intramuscular injection of a mixture of ketamine $(20 \mathrm{mg} / \mathrm{kg})$ and xylazine $(2 \mathrm{mg} / \mathrm{kg}$ ). Anaesthesia was maintained with $0.5 \sim 5 \%$ isoflurane. The burn wound was induced with a soldering iron with a square-shaped tip at $180^{\circ} \mathrm{C}$, held against the skin for $5 \mathrm{~s}$. Each wound was $3 \times 3 \mathrm{~cm} 2$, spaced at a $5 \mathrm{~cm}$ interval, and had a depth of approximately $3 \mathrm{~mm}$. The dorsal region of the minipigs was shaved with an electric clipper and cleaned with an alcohol swab to avoid infection. Full-thickness burns were induced on the dorsal region of minipigs, producing a total of eight wounds induced on each side of the spine line for NC, PC, T1, and T2. Post-surgical pain was managed with a peroral injection of acetaminophen $(20 \mathrm{mg} / \mathrm{kg})$. This study was approved by the Institutional Animal Care and Use Committee (approval number: KIT 1910-0348).

\section{In vitro assay}

The porcine lung macrophage cell line 3D4/2 (ATCC CRL-2845) and the human keratinocyte cell line HacaT (ATCC PCS-200-011) were used for the in vitro assays. The cells were grown at $37^{\circ} \mathrm{C}$ and $5 \% \mathrm{CO} 2$ in culture media containing 10\% foetal bovine serum (Gibco, Waltham, MA, USA) and $1 \%$ penicillinstreptomycin (10,000 unit/mL; Gibco). A total of $20 \mathrm{ng}$ of lipopolysaccharide (LPS, Sigma-Aldrich, St. Louis, MO, USA) were added over a period of $6 \mathrm{~h}$ to induce immune cell stimulation. The bentonite clay was then mixed with the culture media (1:1) and treated with HacaT and 3D4/2.

\section{Quantitative real-time PCR}

Total RNA was isolated manually using the phenol-chloroform method. Reverse transcription reactions were performed using the QuantiNova Reverse Transcription Kit (Qiagen, Hilden, Germany). Quantitative real-time PCR (qRT-PCR) was performed in a $25 \mu \mathrm{L}$ reaction mixture that included $2 \times$ Power SYBR Green PCR Master Mix (Applied Biosystems, Waltham, MA, USA), each primer at a concentration of $0.5 \mu \mathrm{M}$, and QuantStudio 5 Real-Time PCR System (Applied Biosystems). The following amplification parameters were used in the qRT-PCR: an initial denaturation step at $95^{\circ} \mathrm{C}$ for $10 \mathrm{~min}$ followed by 40 cycles of denaturation at $95^{\circ} \mathrm{C}$ for $15 \mathrm{~s}$, annealing and elongation at $60^{\circ} \mathrm{C}$ for $1 \mathrm{~min}$, without the final elongation step. Primer sequences used for qRT-PCR are listed in Table 3. GAPDH was used as an endogenous control. The $2-\triangle \Delta \mathrm{Ct}$ method was used for relative quantification of target genes. 
Table 3

Primers used for quantitative real-time PCR

\begin{tabular}{|c|c|c|c|c|}
\hline Species & $\begin{array}{l}\text { Gene } \\
\text { symbol }\end{array}$ & Primer sequences (from $5^{\prime}$ to $3^{\prime}$ ) & $\begin{array}{l}\text { Length } \\
\text { (bp) }\end{array}$ & Gene Bank ID \\
\hline \multirow[t]{18}{*}{ Porcine } & \multirow[t]{2}{*}{$\operatorname{cox}-2$} & F: TTCAACCAGCAATTCCAATACCA & \multirow[t]{2}{*}{87} & \multirow[t]{2}{*}{ NM_214321.1 } \\
\hline & & R: GAAGGCGTCAGGCAGAAG & & \\
\hline & \multirow[t]{2}{*}{ PTGES } & F: AGAGCATGAAAACCATCACTCC & \multirow[t]{2}{*}{248} & \multirow[t]{2}{*}{ NM_001038631.1 } \\
\hline & & R:CTCAAGGACATTCTGTCAGGTTC & & \\
\hline & \multirow[t]{2}{*}{ CCL2 } & F: CTCCCACACCGAAGCTTGAA & \multirow[t]{2}{*}{120} & \multirow[t]{2}{*}{ NM_214214.1 } \\
\hline & & R: TAATTGCATCTGGCTGGGCA & & \\
\hline & \multirow[t]{2}{*}{ CXCL2 } & F: ATCCAGGACCTGAAGGTGA & \multirow[t]{2}{*}{116} & \multirow[t]{2}{*}{ NM_001001861.2 } \\
\hline & & R: TTCTTCACCATGGGGGCT & & \\
\hline & \multirow[t]{2}{*}{ TGF $\beta$} & F: AGGGCTACCATGCCAATTTCT & \multirow[t]{2}{*}{101} & \multirow[t]{2}{*}{ NM_214015.2 } \\
\hline & & R: CGGGTTGTGCTGGTTGTACA & & \\
\hline & \multirow[t]{2}{*}{ TNFa } & F: ATGAGCACTGAGAGCATGATCCG & \multirow[t]{2}{*}{163} & \multirow[t]{2}{*}{ NM_214022.1 } \\
\hline & & R: CCTCGAAGTGCAGTAGGCAGA & & \\
\hline & \multirow[t]{2}{*}{ IL-1 $\beta$} & F: GAGCATCAGGCAGATGGTGT & \multirow[t]{2}{*}{134} & \multirow[t]{2}{*}{ NM_214055.1 } \\
\hline & & R: CAAGGATGATGGGCTCTTCTTC & & \\
\hline & \multirow[t]{2}{*}{ IL-6 } & $\begin{array}{l}\text { F: } \\
\text { GCTGCTTCTGGTGATGGCTACTGCC }\end{array}$ & \multirow[t]{2}{*}{318} & \multirow[t]{2}{*}{ NM_001252429.1 } \\
\hline & & $\begin{array}{l}\text { R: } \\
\text { TGAAACTCCACAAGACCGGTGGTGA }\end{array}$ & & \\
\hline & \multirow[t]{2}{*}{ GAPDH } & F: ACAGACAGCCGTGTGTTCC & \multirow[t]{2}{*}{62} & \multirow[t]{2}{*}{ NM_001206359.1 } \\
\hline & & R: ACCTTCACCATCGTGTCTCA & & \\
\hline \multirow[t]{7}{*}{ Human } & \multirow[t]{2}{*}{$\mathrm{cox}-2$} & F: GAATGGGGTGATGAGCATGT & \multirow[t]{2}{*}{99} & \multirow[t]{2}{*}{ NM_000963.4 } \\
\hline & & R: GCCACTCAAGTGTTGCACAT & & \\
\hline & \multirow[t]{2}{*}{ IL-1 $\beta$} & F: GTGGCAATGAGGATGACTTGTTC & \multirow[t]{2}{*}{103} & NM_000576.3 \\
\hline & & R: TAGTGGTGGTCGGAGATTCGTA & & \\
\hline & PTGES & F: CTGCTGGTCATCAAGATGTACG & 223 & NM_004878 \\
\hline & & R: GGTTAGGACCCAGAAAGGAGT & & \\
\hline & TGF $\beta$ & F: CCCTGGACACCAACTATTGC & 131 & NM 000660.7 \\
\hline
\end{tabular}




\begin{tabular}{|c|c|c|c|c|}
\hline Species & $\begin{array}{l}\text { Gene } \\
\text { symbol }\end{array}$ & Primer sequences (from $5^{\prime}$ to $3^{\prime}$ ) & $\begin{array}{l}\text { Length } \\
\text { (bp) }\end{array}$ & Gene Bank ID \\
\hline \multicolumn{5}{|c|}{ R: GCAGAAGTTGGCATGGTAGC } \\
\hline & \multirow[t]{2}{*}{ GAPDH } & F: ССАСТССТССАССТTTGАС & 102 & NM 002046.7 \\
\hline & & R: ACCCTGTTGCTGTAGCCA & & \\
\hline
\end{tabular}

\section{Enzyme-linked immunosorbent assay (ELISA)}

The production of prostaglandin e2 (PGE2) in cell lines and skin tissues was determined by a Prostaglandin E2 Parameter Assay Kit (R\&D Systems, Minneapolis, MN, USA). The assay was performed according to the manufacturer's instructions.

\section{Immunohistochemistry}

Tissues were fixed in neutral buffered formalin overnight and embedded in paraffin. Tissue samples were sectioned $(5 \mu \mathrm{m})$, deparaffinized, processed for antigen retrieval, blocked, and incubated with the primary antibody (dilution 1:100) targeting the Ki-67 antigen (cat\#9949, Cell Signalling Technology, MA, USA), VEGF (cat\#ab1316, Abcam, CA, UK) and peroxidase-conjugated secondary antibody. The samples were mounted and photographed using a microscope (LSM800 or AxioVision; Zeiss, Oberkochen, Germany). For comparison among the experimental groups, images were captured at the same exposure time. For the peroxidase-conjugated secondary antibody, 3,3- diaminobenzidine substrate was used, followed by hematoxylin for nuclear counterstaining. Expressions of VEGF and Ki67+ cells were measured using the open-source image analysis tool, Image J software (version $1.53 \mathrm{https}$ ://imagej.nih.gov/ij/index.html, National Institutes of Health, MD, USA).

\section{Masson's trichrome staining}

The experiments were performed according to the manufacturer's protocol (cat\#IFU-2, ScyTek, Logan, UT, USA). Deparaffinized slides were incubated with Weigert's iron hematoxylin, Biebrichscarlet-acid fuchsin solution, phosphomolybdic-phosphotungstic acid solution, and aniline blue solution. The slides were then rinsed with $1 \%$ acetic acid solution. Collagen connective tissue showed a bluish colour. Dermal regeneration was calculated using the following formula: $100 \times$ collagen deposition (blue colour) length/total dermis layer length.

\section{Statics}

The comparison analysis was performed using Prism 7 (GraphPad Software, San Diego, CA, USA). All graphs are presented as the mean \pm standard deviation. All experiments were performed in triplicate. Statistical analyses were performed using one-way analysis of variance and two-tailed Student's t-test. Differences were considered statistically significant at $p<0.05$.

\section{Results}




\section{A novel bentonite complex induces skin regeneration in a minipig burn wound model}

Macroscopic observation revealed that the wound areas were not significantly different between the bentonite complex and control groups until day 21 (Figure 1). However, scabs were removed from the skin surface in the bentonite complex group compared with the NC group. Histological analysis showed that collagen deposition significantly increased in the T1 $(1 \mathrm{mg} / \mathrm{mL}), T 2(6 \mathrm{mg} / \mathrm{mL})$, and PC (silver sulfadiazine) groups than in the NC (saline) group (Figure 2). Consistent with the macroscopic findings, few scabs were detected in the bentonite complex treatment groups, indicating that the bentonite complex induced clearance of scabs. Ki67+ cells significantly increased in the T1 and T2 groups, and the number of cells in the T1 group was greater than that in the PC group (Figure 3). Furthermore, the relative expression of VEGF also significantly increased in both the T1 and T2 groups in contrast to that in the NC group (Figure 4). Thus, we infer that the bentonite complex promotes skin regeneration in burn wounds by inducing collagen synthesis, cell proliferation, and angiogenesis.

\section{A novel bentonite complex inhibits COX-2-mediated inflammatory response on the burn wound}

To identify skin regeneration by the anti-inflammatory effect of the bentonite complex, the gene expression of the inflammatory markers was analysed. Expression of interleukin 1 beta $(I L-1 \beta)$ and $C O X-2$ was significantly downregulated in T1, T2, and PC compared with that in the NC group (Figure 5A). In addition, the expression of the anti-inflammatory cytokine interleukin 10 (IL-10) significantly increased in $\mathrm{T} 1, \mathrm{~T} 2$, and PC in contrast to that in the NC group. Consistent with the previous result, the production of PGE2, a potent inflammatory mediator synthesised by COX-2, significantly decreased in the T1, T2, and PC groups in all minipigs (Figure 5B). Therefore, the bentonite complex inhibited the inflammatory response in burn wounds by regulating the COX-2 pathway.

Bentonite clay mediates anti-inflammatory response in vitro.

To identify the anti-inflammatory effect of bentonite clay in the bentonite complex, we analysed the expression of COX-2 mediated inflammatory cytokines and chemokines in HacaT keratinocytes and $3 D 4 / 2$ macrophage cell lines. qRT-PCR results showed that the expression of $I L-1 \beta, C O X-2$, and prostaglandin E synthase (PTGES) in 3D4/2 macrophage cells significantly decreased in all bentonite treatment groups. $I L-10$, an anti-inflammatory cytokine, also decreased but without statistical significance (Figure 6A). In HacaT keratinocytes, the expression of the same panels decreased in all bentonite treatment groups. However, $I L-10$ significantly increased, contrary to the results of 3D4/2. PGE2 secretion in both HacaT and 3D4/2 cells decreased by bentonite (Figure 6B).

To observe the direct anti-inflammatory effect of bentonite on immune cells, we treated 3D4/2 macrophages with LPS to mimic the inflammatory response in vitro. As a result, the expression of $I L-1 \beta$, COX-2, PTGES, and other cytokines; tumour necrosis factor alpha (TNFa); interleukin 6 (IL-6); C-C motif 
chemokine ligand 2 (CLL2); and C-X-C chemokine ligand 2 (CXCL2) were inhibited by treatment with bentonite clay (Figure 7).

\section{Discussion}

By inducing tissue regeneration without any toxicological response, an in vivo study was able to confirm the therapeutic effect of a novel bentonite complex in burn wounds. Cell proliferation, angiogenesis, and collagen deposition were activated in burn wounds after treatment with the bentonite complex. In addition, the quantity of scabs on the surface of wounds visibly decreased (especially in males) in both macroscopic observation and Masson's trichrome staining. This suggests that the bentonite complex creates moist conditions, which are beneficial to cell growth, and conditions conducive to tissue reconstruction [31, 32].

The anti-inflammatory function of the bentonite complex was also detected at the gene and protein levels. IL-1 $\beta$, a potent inflammatory cytokine that induces COX-2 transcription through NF-KB signalling, was increased in burn wounds by the bentonite complex. Production of PGE2 synthesised by the COX-2 enzyme was also significantly inhibited in burn wounds. In addition, the bentonite complex significantly increased gene expression of IL-10, an anti-inflammatory cytokine, in burn wounds (Figure 5A). Taken together, the in vivo study showed that the bentonite complex improved tissue repair and inhibited the inflammatory response in burn wounds by inhibiting the COX-2 pathway (Figure 8A).

An in vitro study identified that bentonite clay, a major component of the bentonite complex, inhibited the expression of $I L-1 \beta, C O X-2$, and PTGES in 3D4/2 macrophages. Interestingly, the expression of $I L-10$ was significantly increased in keratinocytes after treatment with bentonite clay. Some studies have reported that IL-10 induces tissue repair as well as an anti-inflammatory effect [33, 34].

Other studies on inflammatory conditions induced by immune cells have consistently demonstrated the anti-inflammatory effect of bentonite clay. Expressions of COX-2 mediated cytokines and chemokines significantly increased in 3D4/2-treated LPS only. However, they were all suppressed by treatment with the bentonite clay solution, even when compared with the NC group. These findings indicate that the bentonite clay regulated COX-2 signalling in macrophages with the paracrine assistance of IL-10 released from keratinocytes (Figure 8B).

However, in the macroscopic images, we could not observe any significant wound contraction after treatment with the bentonite complex (Figure 1). Our experimental schedule for wound healing may not have been sufficient for complete tissue remodelling, which is the final phase of skin regeneration [35]. A study reported that wound contraction could be delayed by physiological stress involved in myofibroblast differentiation, independent of the anti-inflammatory process [36].

\section{Conclusion}


Recently, bentonite clay has become a commonly used raw material due to its possible therapeutic effects. Using the minipig burn wound model, we verified the therapeutic effects of the bentonite complex in the tissue repair mechanism (Figure 8) [12]. This study demonstrated the therapeutic efficacy and clinical safety of a novel bentonite complex and identified the anti-inflammatory effect of bentonite clay, providing a basis for developing bentonite-based products for medical and cosmetic use.

\section{Abbreviations}

\section{CCL2}

C-C motif chemokine Ligand 2

COX-2

Cyclooxygenase 2

CXCL2

C-X-C chemokine ligand 2

ELISA

Enzyme-linked immunosorbent assay

$\mathrm{IHC}$

Immunohistochemistry

ICP-OES

Inductively coupled plasma optical emission spectroscopy

IL-1 $\beta$

Interleukin 1 beta

IL-10

Interleukin 10

IL-6

Interleukin 6

LPS

Lipopolysaccharide

NC

Negative control

PGE2

Prostaglandine E2

PTGES

Prostaglandine E synthase

PC

Positive control

qRT-PCR

Quantitative real-time PCR

SPF

Specific pathogen free 
TNFa

Tumour necrosis factor alpha

TBSA

Total body surface area

\section{Declarations}

Ethics approval and consent to participate

Not applicable

\section{Consent for publication}

All authors have consented to the submission of this manuscript for publication

\section{Availability of data and materials}

For all data generated in this study requests, please contact the corresponding author.

\section{Competing interests}

The authors declare that they have no competing interests

Funding

This work was supported by the Korea Institute of Toxicology (KIT, Korea) grant funded by the Ministry of science and ICT (MIST, Korea). [Project number: KK-2109-01]

Authors' contribution

JHH designed and coordinated the research, JYL primarily conducted research and wrote manuscript, HNS performed histological analysis. KYC provided the biomaterials and their information. CWS proofread and commented on and manuscript. All authors read and approved the final manuscript.

\section{Acknowledgements}

Not applicable

\section{References}

1. Alden NE, Rabbitts A, Yurt RW. Contact burns: is further prevention necessary? J Burn Care Res 2006;27(4):472-5. doi: 10.1097/01.BCR.0000226102.43343.0A.

2. Evers LH, Bhavsar D, Mailänder P. The biology of burn injury. Exp Dermatol. 2010;19(9):777-83. doi: 10.1111/j.1600-0625.2010.01105.x. 
3. Tiwari VK. Burn wound: How it differs from other wounds? Indian J Plast Surg. 2012;45:364-73. DOI: 10.4103/0970-0358.101319.

4. Singer AJ, Boyce ST. Burn wound healing and tissue engineering. J Burn Care Res. 2017;38:e605-13. DOI: $10.1097 / B C R .0000000000000538$.

5. Eming SA, Krieg T, Davidson JM. Inflammation in wound repair: Molecular and cellular mechanisms. J Invest Dermatol. 2007;127:514-25. DOI: 10.1038/sj.jid.5700701.

6. Rodrigues M, Kosaric N, Bonham CA, et al. Wound healing: A cellular perspective. Physiol Rev. 2019;99:665-706. DOI: 10.1152/physrev.00067.2017.

7. Cañedo-Dorantes L, Cañedo-Ayala M. Skin acute wound healing: A comprehensive review. Int J Inflam. 2019:3706315. DOI: 10.1155/2019/3706315.

8. Cancio LC. Topical Antimicrobial Agents for Burn Wound Care: History and Current Status. 2021. https://doi.org/10.1089/sur.2020.368. Accessed 12 Jan 2021.

9. Momcilović D. [Topical agents used in the treatment of burns]. Med Pregl. 2002;55(3-4):109-13. doi: 10.2298/mpns0204109m.

10. Moosavi M. Bentonite clay as a natural remedy: A brief review. Iran J Public Health. 2017;46:117683.

11. Srasra E, Bekri-Abbes I. Bentonite Clays for Therapeutic Purposes and Biomaterial Design. Curr Pharm Des. 2020;26(6):642-649. doi: 10.2174/1381612826666200203144034.

12. Babahoum N, Hamou MO. Characterization and purification of Algerian natural bentonite for pharmaceutical and cosmetic applications. BMC Chem. 2021;15(1):50. doi: 10.1186/s13065-02100776-9.

13. Park JH, Shin HJ, Kim MH, Kim JS, Kang N, Lee JY, et al. Application of montmorillonite in bentonite as a pharmaceutical excipient in drug delivery systems. J Pharm Investig. 2016;46(4):363-375. doi: 10.1007/s40005-016-0258-8.

14. Williams LB, Haydel SE. Evaluation of the medicinal use of clay minerals as antibacterial agents. Int Geol Rev. 2010;52:745-70. DOI: 10.1080/00206811003679737.

15. Cervini-Silva J, Ramírez-Apan MT, Kaufhold S, Ufer K, Palacios E, Montoya A.Role of bentonite clays on cell growth. Chemosphere. 2016;149:57-61. DOI: 10.1016/j.chemosphere.2016.01.077.

16. Nones J, Riella HG, Trentin AG, Nones J. Effects of bentonite on different cell types: A brief review. Appl Clay Sci. 2015;105:225-30. DOI: 10.1016/j.clay.2014.12.036.

17. Seaton M, Hocking A, Gibran NS. Porcine models of cutaneous wound healing. ILAR J. 2015;56, 127-138. doi: 10.1093/ilar/ilv016.

18. Alex A, Chaney EJ, Žurauskas M, Criley JM, Spillman DR Jr, Hutchison PB, et al.. In vivo characterization of minipig skin as a model for dermatological research using multiphoton microscopy. Exp Dermatol. 2020;29(10):953-960. doi: 10.1111/exd.14152.

19. Summerfield A, Meurens F, Ricklin ME. The immunology of the porcine skin and its value as a model for human skin. Mol Immunol. 2015;66(1):14-21. doi: 10.1016/j.molimm.2014.10.023. 
20. Branski LK, Mittermayr R, Herndon DN, Norbury WB, Masters OE, Hofmann M, et al. A porcine model of full-thickness burn, excision and skin autografting. Burns. 2008;34(8):1119-27. doi: 10.1016/j.burns.2008.03.013.

21. Singer AJ, Hirth D, McClain SA, Crawford L, Lin F, Clark RA. Validation of a vertical progression porcine burn model. J Burn Care Res. 2011;32(6):638-46. doi: 10.1097/BCR.0b013e31822dc439.

22. Gantwerker EA, Hom DB. Skin: histology and physiology of wound healing. Facial Plast Surg Clin North Am. 2011;19(3):441-53. doi: 10.1016/j.fsc.2011.06.009.

23. La Rosa S, Bonzini M, Sciarra A, Asioli S, Maragliano R, Arrigo M, et al. Exploring the Prognostic Role of Ki67 Proliferative Index in Merkel Cell Carcinoma of the Skin: Clinico-Pathologic Analysis of 84 Cases and Review of the Literature. Endocr Pathol. 2020;31(4):392-400. doi: 10.1007/s12022-02009640-3.

24. Murukesh N, Dive C, Jayson GC. Biomarkers of angiogenesis and their role in the development of VEGF inhibitors. Br J Cancer. 2010;102(1):8-18. doi: 10.1038/sj.bjc.6605483.

25. Bainbridge P. Wound healing and the role of fibroblasts. J Wound Care. 2013;22(8):407-8, 410-12. doi: 10.12968/jowc.2013.22.8.407.

26. Bogaty P, Brophy JM, Noel M, Boyer L, Simard S, Bertrand F, et al. Impact of prolonged cyclooxygenase-2 inhibition on inflammatory markers and endothelial function in patients with ischemic heart disease and raised C-reactive protein: a randomized placebo-controlled study. Circulation. 2004;110(8):934-9. doi: 10.1161/01.CIR.0000139338.12464.5F.

27. Kawahara K, Hohjoh H, Inazumi T, Tsuchiya S, Sugimoto Y. Prostaglandin E2-induced inflammation: Relevance of prostaglandin E receptors. Biochim Biophys Acta. 2015;1851(4):414-21. doi: 10.1016/j.bbalip.2014.07.008.

28. Rieppo L, Janssen L, Rahunen K, Lehenkari P, Finnilä MAJ, Saarakkala S. Histochemical quantification of collagen content in articular cartilage. PLoS One. 2019; 14(11): e0224839.

29. Colombo I, Sangiovanni E, Maggio R, Mattozzi C, Zava S, Corbett Y, et al. HaCaT. Cells as a Reliable In Vitro Differentiation Model to Dissect the Inflammatory/Repair Response of Human Keratinocytes. Mediators Inflamm. 2017;2017:7435621. doi: 10.1155/2017/7435621.

30. Albanesi C, Madonna S, Gisondi P, Girolomoni G. The Interplay Between Keratinocytes and Immune Cells in the Pathogenesis of Psoriasis. Front. Immunol. 2018. https://doi.org/10.3389/fimmu.2018.01549. Accessed 06 July 2018.

31. Ousey K, Cutting KF, Rogers AA, Rippon MG. The importance of hydration in wound healing: reinvigorating the clinical perspective. J Wound Care. 2016;25(3):122, 124-30. doi: 10.12968/jowc.2016.25.3.122.

32. Field FK, Kerstein MD. Overview of wound healing in a moist environment. Am J Surg. 1994;167(1A):2S-6S. doi: 10.1016/0002-9610(94)90002-7.

33. Opal SM, DePalo VA. Anti-inflammatory cytokines. Chest 2000;117;1162-72. DOI: 10.1378/chest.117.4.1162. 
34. King A, Balaji S, Le LD, Crombleholme TM, Keswani SG. Regenerative Wound Healing: The Role of Interleukin-10. Adv Wound Care (New Rochelle). 2014; 3(4): 315-323. doi: $10.1089 /$ wound. 2013.0461

35. Bowden LG, Byrne HM, Maini PK, Moulton DE. A morphoelastic model for dermal wound closure. Biomech Model Mechanobiol. 2016;15(3):663-81.

36. Horan MP, Quan N, Subramanian SV, Strauch AR, Gajendrareddy PK, Marucha PT. Impaired wound contraction and delayed myofibroblast differentiation in restraint-stressed mice. Brain Behav Immun. 2005;19(3):207-16. doi: 10.1016/j.bbi.2004.09.004.v.

\section{Figures}




\begin{tabular}{|c|c|c|c|c|c|c|}
\hline \multirow{2}{*}{ Male } & \multicolumn{2}{|c|}{ Day 2} & \multicolumn{2}{|c|}{ Day 10} & \multicolumn{2}{|c|}{ Day 21} \\
\hline & Left & Right & Left & Right & Left & Right \\
\hline $\mathrm{NC}$ & & & & & & \\
\hline PC & & & & & & \\
\hline T1 & & & & & & \\
\hline $\mathrm{T} 2$ & & & & & & \\
\hline & & & & & 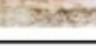 & \\
\hline
\end{tabular}

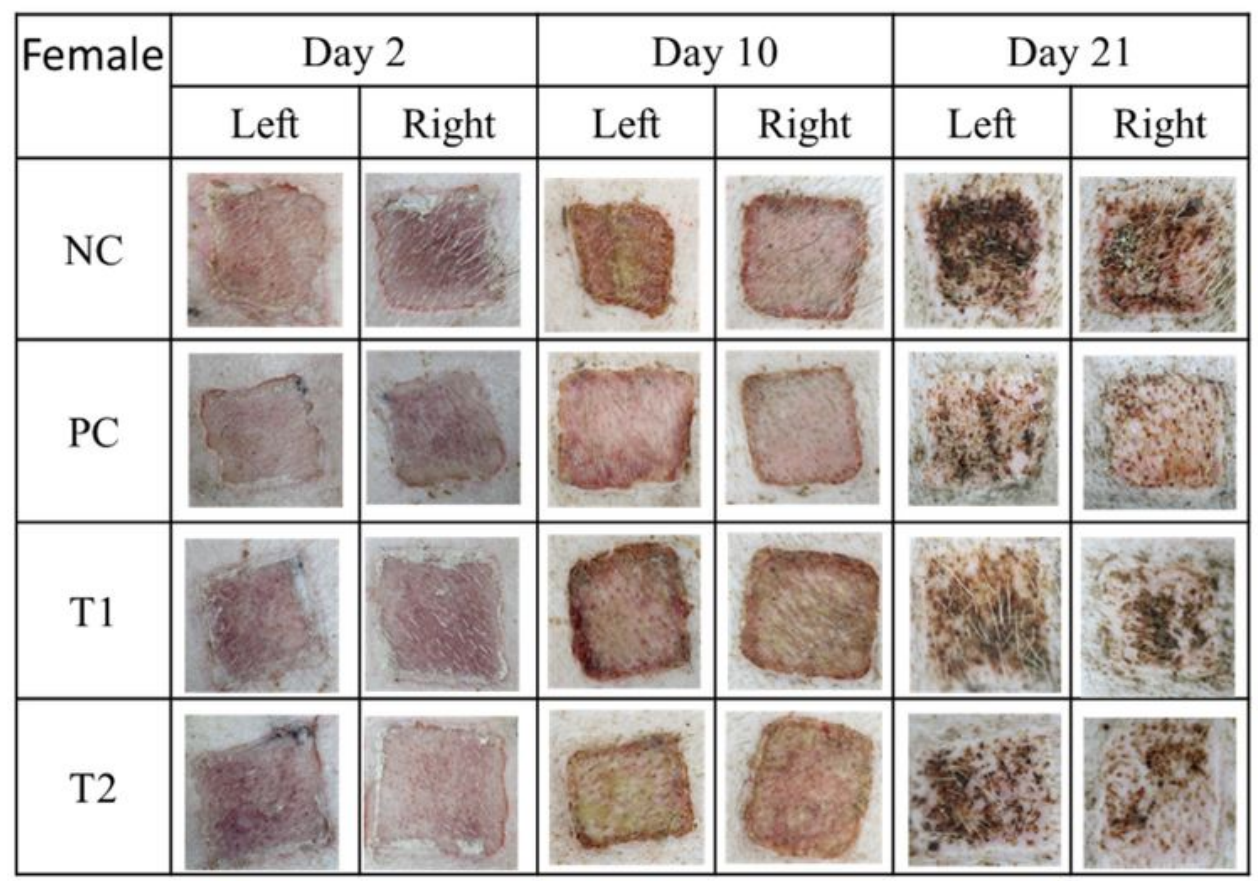

\section{Figure 1}

Macroscopic observation of minipig burn wounds. The pictures of wounds were taken on days 2, 10 and 21. The burns were induced on both sides of the back and sized $3 \times 3 \mathrm{~cm} 2$. The bentonite complex and control agents were equally applied in a volume of $1 \mathrm{~mL}$ (NC, saline; PC, Silver sulfadiazine $1 \% \mathrm{cream}$; T1 and $\mathrm{T} 2,1$ and $6 \mathrm{mg} / \mathrm{mL}$ of a novel bentonite complex). 


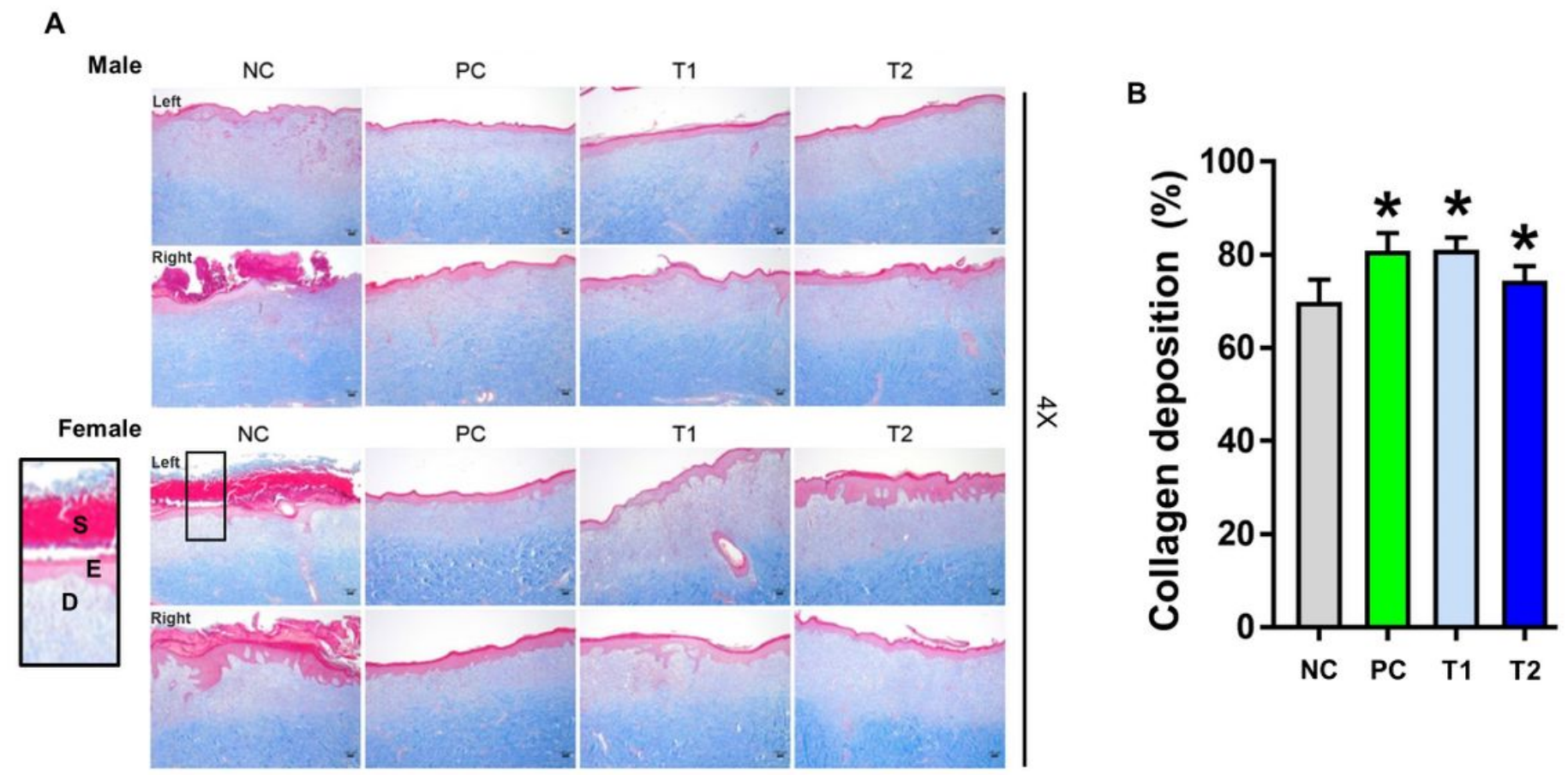

Figure 2

Masson's trichrome staining of the dermis layer of burn wounds. (a) Microscopic observation of collagen deposition in the burn wounds. Collagen-rich fibrotic region was marked in blue. Cytoplasm and muscle fibers were marked in red. $\mathrm{S}=\mathrm{Scab}, \mathrm{E}=$ Epidermis, $\mathrm{D}=$ Dermis. (b) Percentage of collagen deposition ( $\mathrm{Y}$ axis) was determined by measuring the depth of collagen $(n=4)$. All data are represented as mean \pm standard deviation. Scale bars: $100 \mu \mathrm{m}$. ( ${ }^{*} \leq 0.05$, compared to the NC group).

A

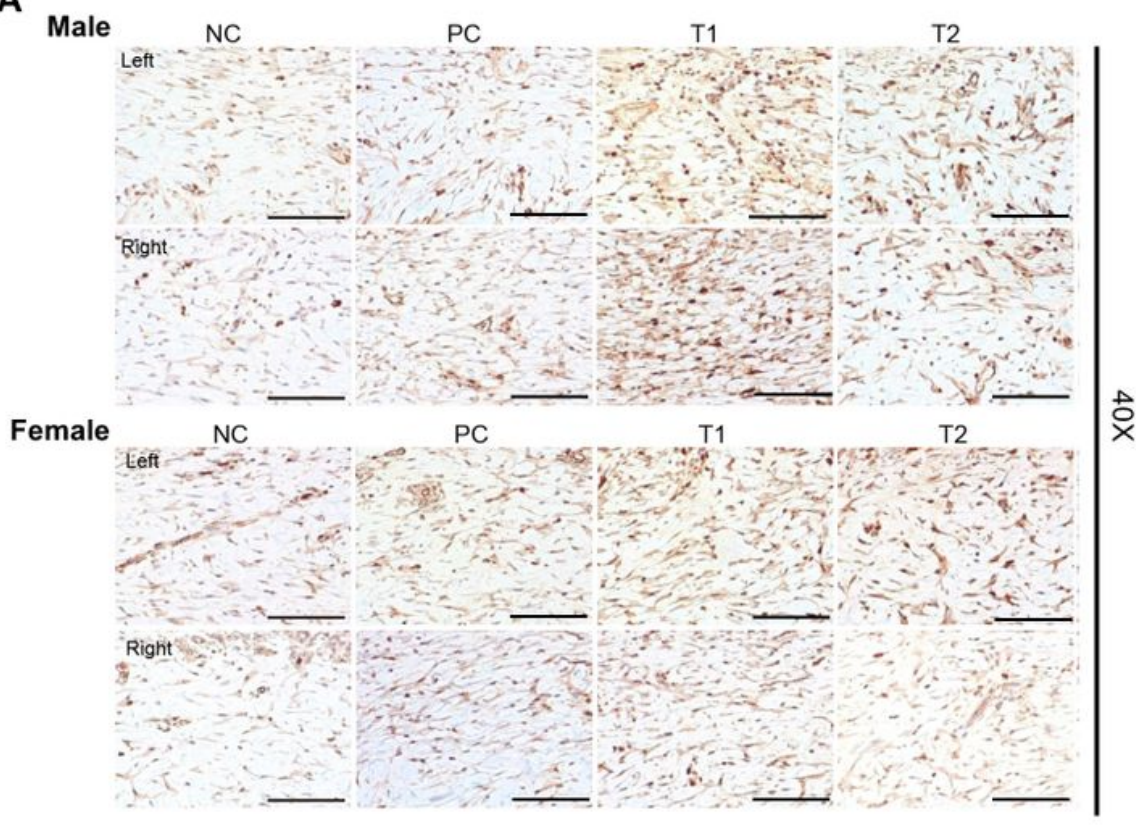

B

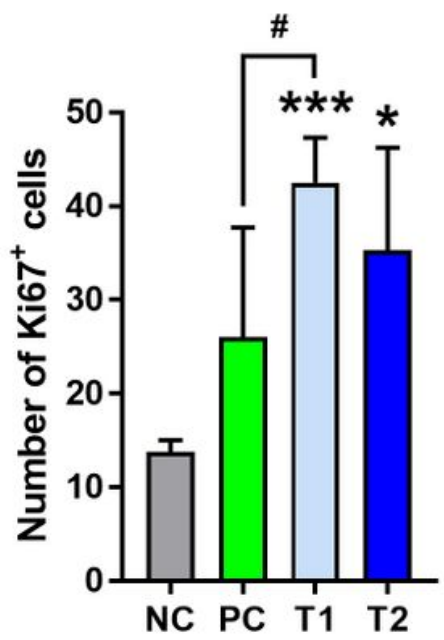


Figure 3

Immunohistochemistry analysis of Ki67 expression in burn wounds. (a) Microscopic images of Ki67 staining in the burn wounds. Ki67 antigens were marked in brown, and nucleus were counterstained with hematoxylin (blue). (b) The number of Ki67+ cells (Y-axis) was determined by counting the nuclei of Ki67+ cells $(n=4)$. All data are represented as mean \pm standard deviation. Scale bars: $100 \mu m$. $\left({ }^{*} p \leq\right.$ 0.05 , $\star \star \star ~ p \leq 0.001$ compared to the NC group; \# $p \leq 0.05$, compared to PC group).
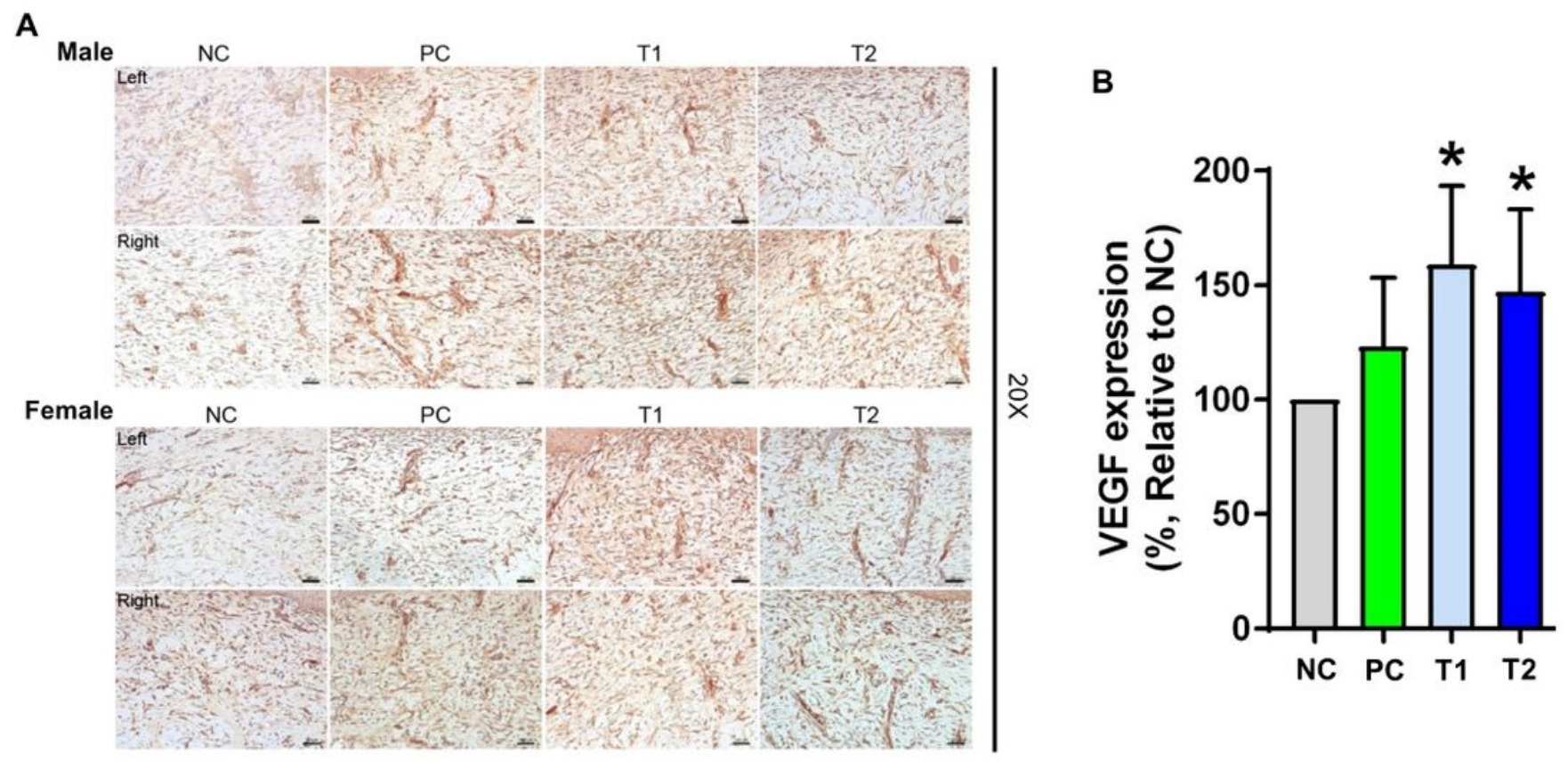

\section{Figure 4}

Immunohistochemistry analysis of VEGF expression in burn wounds. (a) Microscopic images of VEGF staining in the burn wounds. VEGF were marked in brown and nuclei were marked in blue. (b) Relative expression of VEGF ( $Y$-axis) was determined by measuring brown area $(n=4)$. All data are represented as mean \pm standard deviation. Scale bars: $100 \mu \mathrm{m}$. ( $\mathrm{p} \leq 0.05$, compared to NC group). 

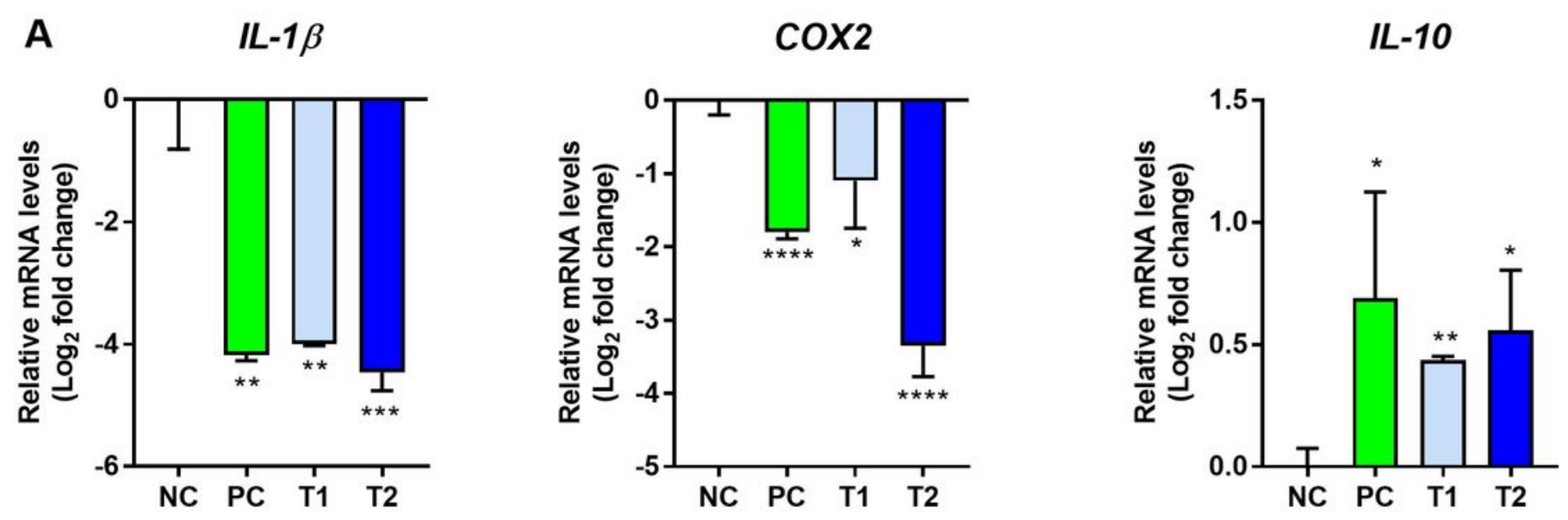

B

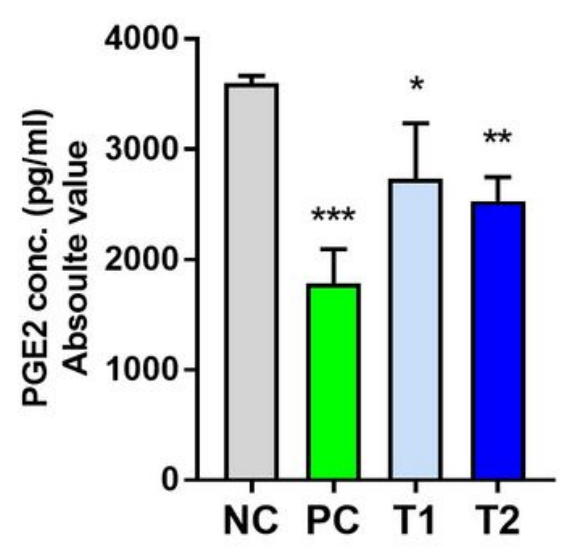

Figure 5

Gene and protein expression of inflammatory cytokines in the burn wounds. (A) Expressions of IL-1 $\beta$, COX-2, and IL-10 were analysed using qRT-PCR. (B) Comparison of PGE2 concentration in burn wounds of minipigs using ELISA. All samples were run in triplicate. All data are represented as mean \pm standard

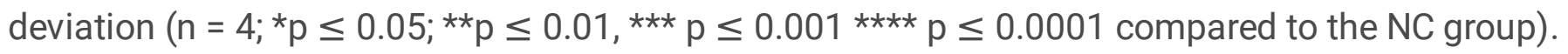


(a)
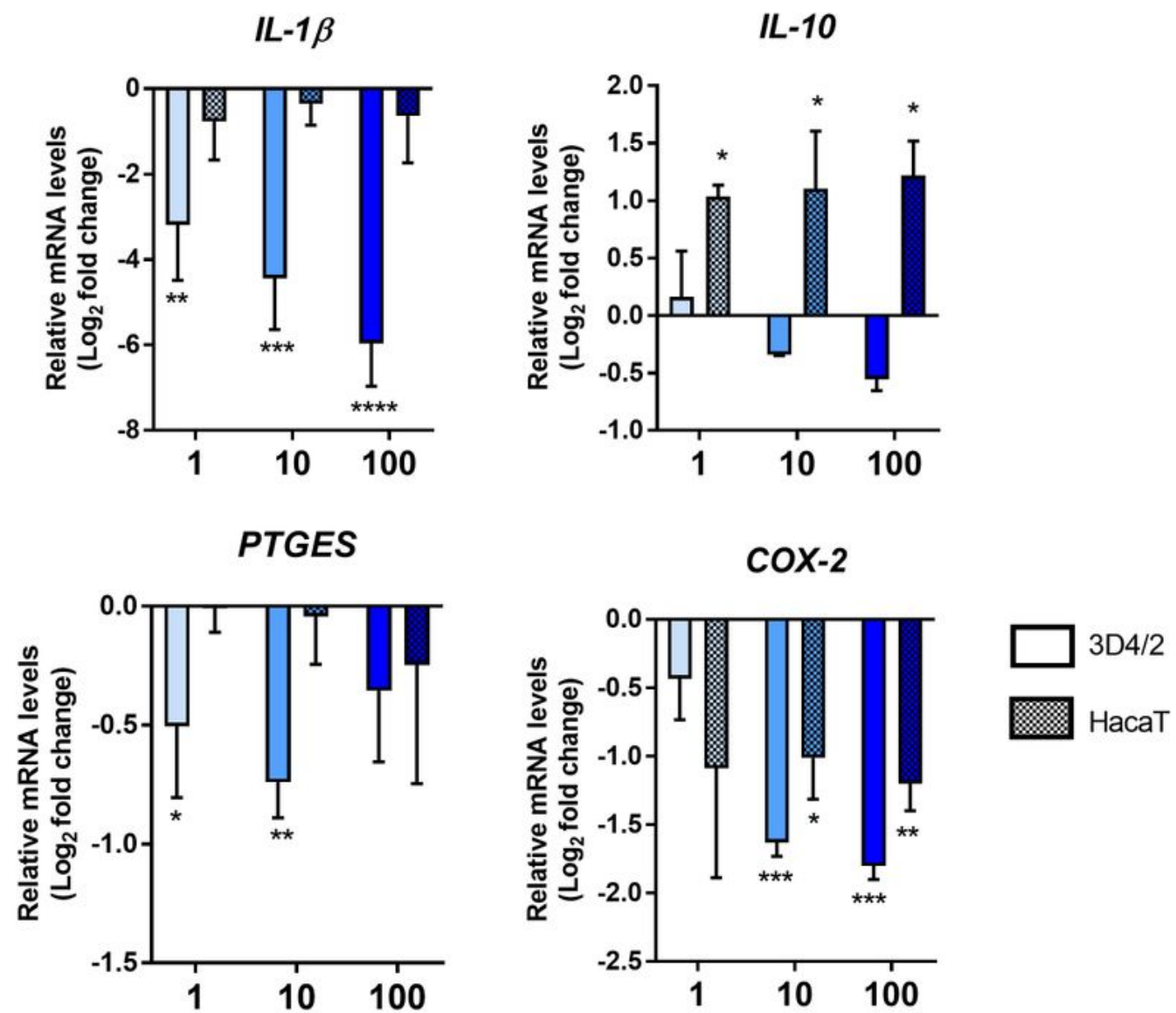

(b)

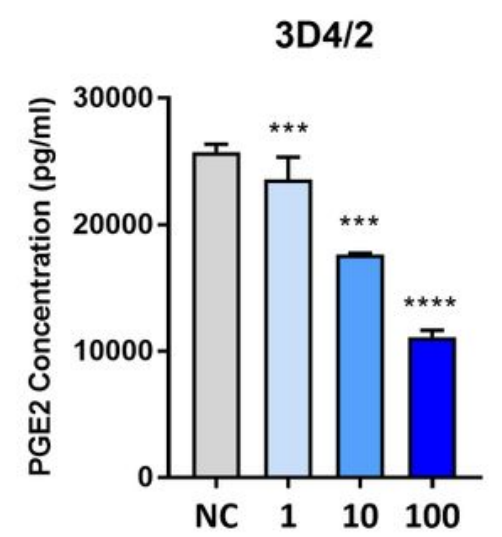

HacaT

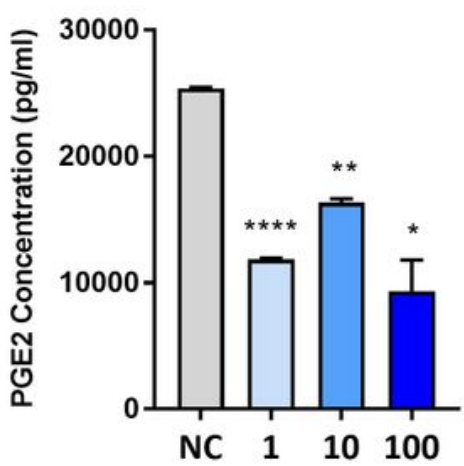

Figure 6

Gene and protein expression analysis of COX-2 mediated inflammatory. cytokines in HacaT and 3D4/2. (a) qRT-PCR result represents COX-2 mediated inflammatory gene expression of HacaT and 3D4/2 after treatment of the water-soluble fraction of the bentonite solution. (b) ELISA result measured production of PGE2 from HacaT and 3D4/2. All samples were run in triplicate. X-axis indicates the concentration of 
bentonite clay $(\mu \mathrm{g} / \mathrm{ml})$. All data are represented as mean \pm standard deviation $\left(n=3 ; \star^{\star} \leq 0.05 ; * \star p \leq\right.$ $0.01 ; * \star * p \leq 0.005 ; * \star \star \star p \leq 0.001$, compared to the NC group).
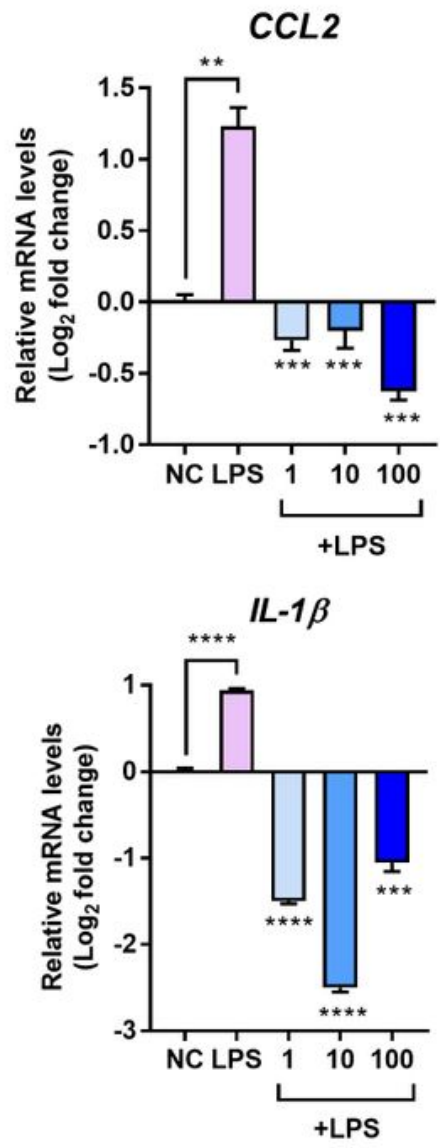

$T N F \alpha$

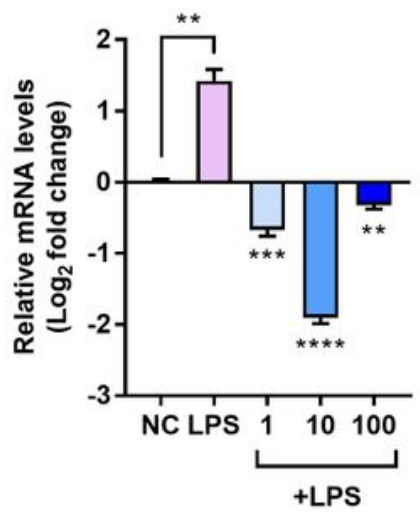

CXCL2
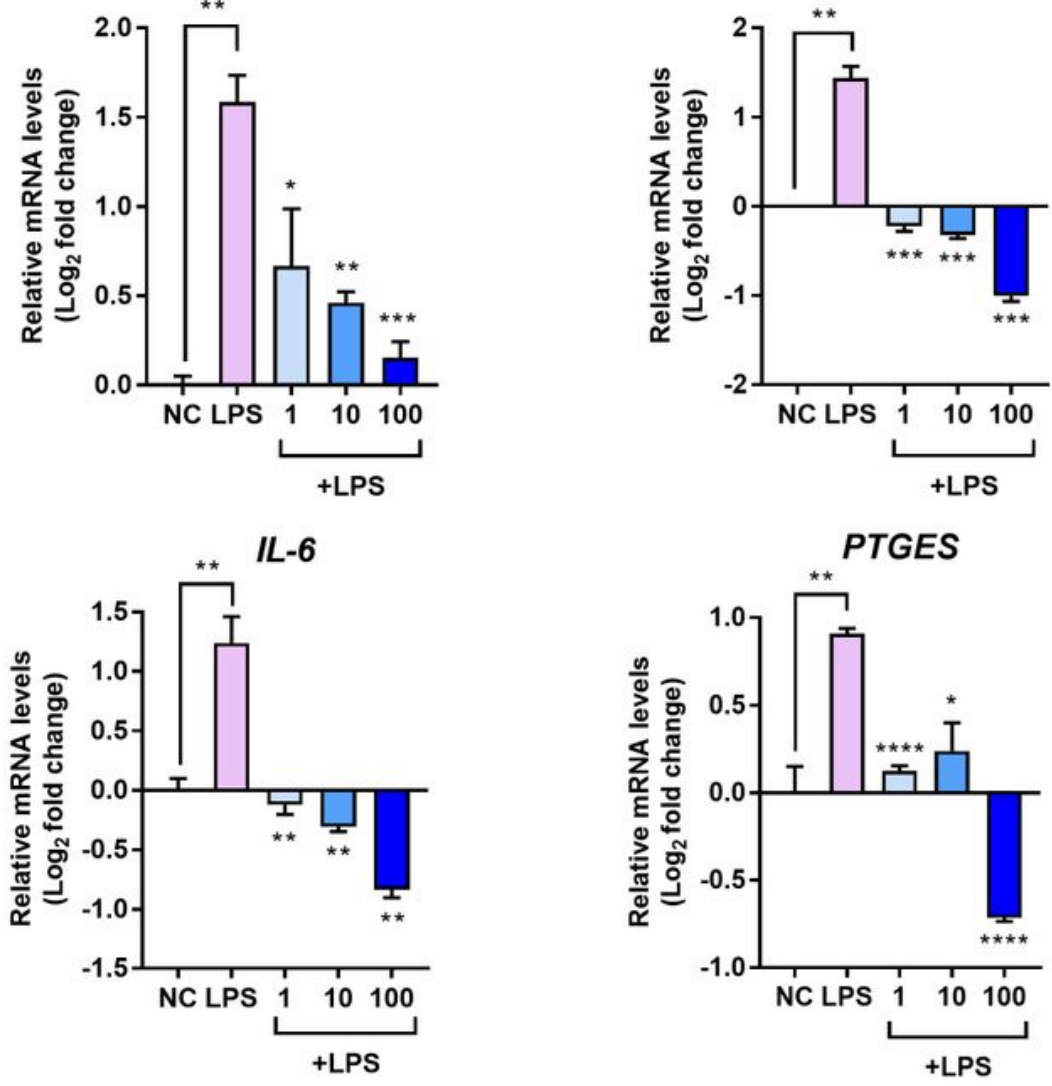

\section{Figure 7}

Gene expression analysis of inflammatory cytokines in LPS-induced 3D4/2. The graph represents changes of inflammatory gene expression in LPS-induced and conventional 3D4/2 cells after treatment with water-soluble fraction of the bentonite solution. All samples were run in triplicate. All data are 
represented as mean \pm standard deviation $\left(n=3 ;{ }^{*} p \leq 0.05 ;{ }^{* \star} p \leq 0.01 ; * \star \star p \leq 0.005 ; * \star \star \star p \leq 0.001\right.$, compared with only treatment of LPS group).

\section{(a) In vivo}

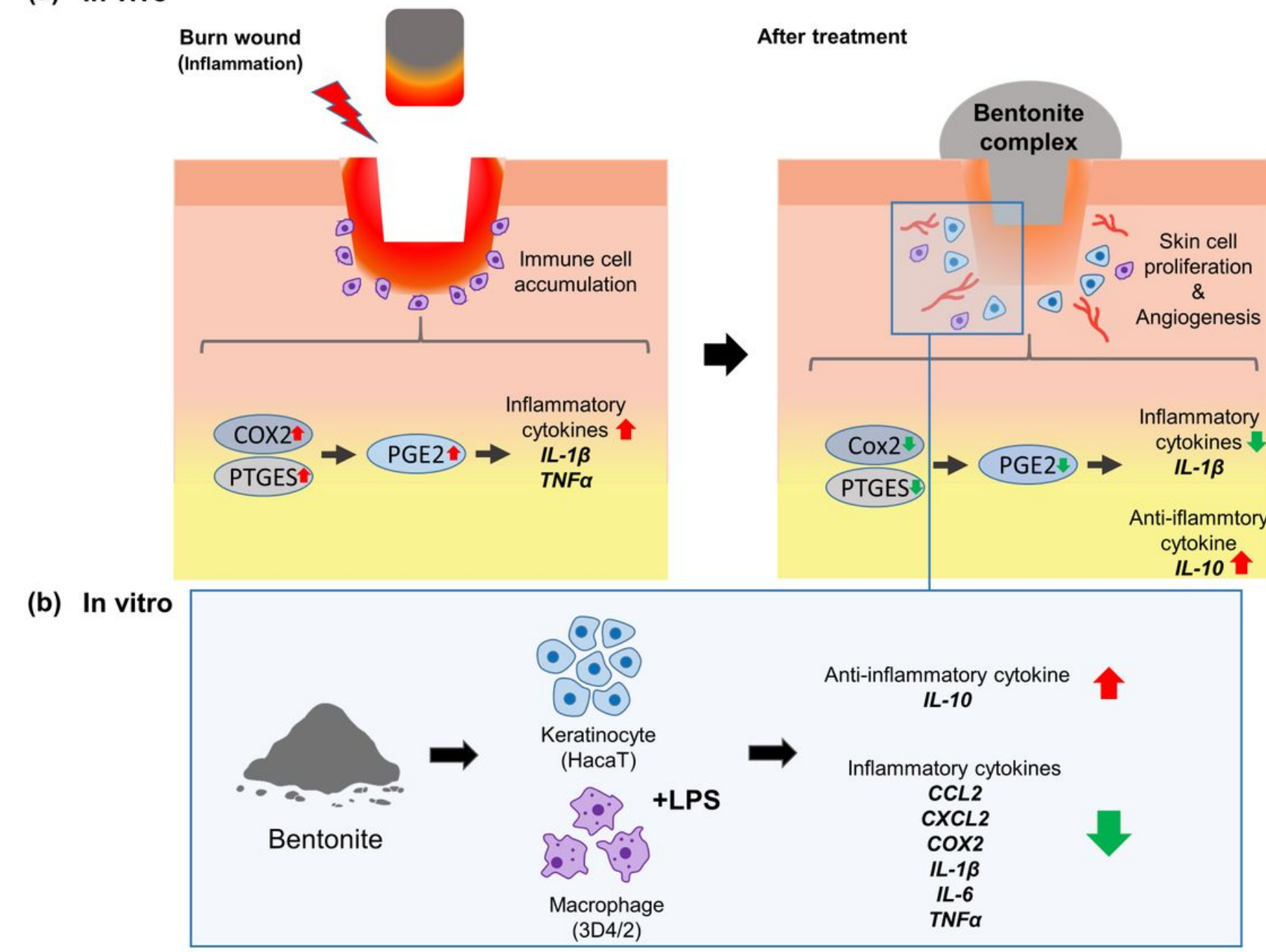

\section{Figure 8}

Graphical summary (a) In vivo assay evaluated the therapeutic effect of a novel bentonite complex on the burn wound of a minipig by promoting tissue regeneration and inhibiting COX-2 mediated inflammatory response. (b) In vitro assay identified that the bentonite clay in the bentonite complex regulated inflammatory signalling by inhibiting COX-2 / PGE2 axis in inflammatory macrophages and activating anti-inflammation in keratinocytes. 